\title{
Toll-Like Receptor 9 Is a Novel Biomarker for Esophageal Squamous Cell Dysplasia and Squamous Cell Carcinoma Progression
}

\author{
Heikki Takala ${ }^{a}$ Joonas H. Kauppila ${ }^{a-c}$ Ylermi Soini ${ }^{b, d}$ Katri S. Selander ${ }^{c, f}$ \\ Katri S. Vuopala e Petri P. Lehenkaria, c Juha Saarnio ${ }^{a}$ Tuomo J. Karttunen ${ }^{b}$ \\ Departments of a Surgery, ${ }^{b}$ Pathology and ${ }^{c}$ Anatomy and Cell Biology, University of Oulu, Oulu, ${ }^{d}$ Department of \\ Clinical Pathology and Forensic Medicine, University of Eastern Finland, Kuopio, and e Department of Pathology, \\ University Hospital of Lapland, Rovaniemi, Finland; ${ }^{f}$ Division of Hematology-Oncology, Department of Medicine, \\ University of Alabama at Birmingham, Birmingham, Ala., USA
}

\author{
Key Words \\ Epithelium $\cdot$ Pattern recognition receptors $\cdot$ Toll-like \\ receptor $9 \cdot$ Esophagus $\cdot$ Squamous cell dysplasia $\cdot$ \\ Squamous cell carcinoma
}

\begin{abstract}
Background: Stimulation of Toll-like receptor 9 (TLR9) has been linked to invasion in various cancer cells in vitro. We investigated TLR9 expression in normal, dysplastic and malignant esophageal squamous epithelium. Methods: TLR9 expression was analyzed by immunohistochemistry in 46 cases of esophageal squamous cell carcinoma, including 12 cases with adjacent squamous dysplasia and 24 cases with normal esophageal epithelium. TLR9 expression was compared with tumor grade, stage, proliferation, apoptosis and vascular density. Results: In normal esophageal squamous epithelium, TLR9 staining intensity decreased linearly from the basal layers to the superficial layers $(p<0.001)$. Strong TLR9 expression was detected across full thickness of highgrade dysplasia, the intensity clearly differing from the normal squamous epithelium and squamous cell carcinoma $(p<0.001)$. All squamous cell carcinomas exhibited TLR9 expression that was positively associated with a high grade
\end{abstract}

$(p<0.05)$, the presence of lymph node metastases $(p<0.05)$ and previously undetected distant metastases $(p<0.05)$. Conclusions: Expression of TLR9 in the basal parts of normal esophageal epithelium suggests a role related to cell proliferation and differentation. TLR9 upregulation detected in dysplastic epithelium and in disseminated carcinomas indicates that this protein may serve as a novel marker for esophageal squamous dysplasia and carcinoma with metastatic potential.

Copyright $\odot 2011$ S. Karger AG, Basel

\section{Introduction}

Toll-like receptors (TLR) are transmembrane, pathogen-recognizing receptors that mediate innate immune responses when exposed to pathogen-associated molecular patterns, such as bacterial lipopolysaccharide or microbial RNA or DNA [1]. Thus far, 13 TLRs have been identified in mammals and 10 in humans [2].

H.T. and J.H.K., as well as P.P.L., J.S. and T.J.K. contributed equally to this work.

\section{KARGER \\ Fax +41613061234 \\ E-Mail karger@karger.ch}

www.karger.com
(C) 2011 S. Karger AG, Basel

1662-811X/11/0036-0631\$38.00/0

Accessible online at:

www.karger.com/jin
Dr. Joonas H. Kauppila

Department of Pathology, University of Oulu

PO Box 5000

FI-90014 Oulu (Finland)

Tel. +358 8537 6369, E-Mail joonas.kauppila@oulu.fi 
Members of the TLR9 subfamily (TLR7 to TLR9) and TLR3 are expressed intracellularly, while the other TLRs are expressed on the cell surface. TLR9 is localized to the endoplasmic reticulum, from where it is translocated for ligand recognition to the endosomal/lysosomal compartment. This endosomal localization is essential in avoiding the recognition of 'self'-nucleic acids [3]. Initially, TLR9 was reported to recognize unmethylated CpG sequences within bacterial DNA [4]. Recent findings suggest that in addition to the microbial DNA and synthetic CpG-ODN-containing ligands, also vertebrate DNA or self-DNA can be recognized by TLR9, and this contributes to the pathophysiology of various autoimmune diseases such as psoriasis and systemic lupus erythematosus [5-8]. Currently, very little is known about the regulation of TLR9 expression and its actual role in cancer cells.

High expression of TLR9 has been detected in various cancers, for example lung, breast, gastric and prostate cancers [9-12]. Furthermore, treatment of TLR9-expressing cancer cells with synthetic TLR9 ligands that are reminiscent of bacterial DNA increases the invasion of breast and prostate cancer cells in vitro [10, 11]. Ilvesaro et al. [13] recently demonstrated that this invasive effect is indeed mediated via TLR9. Various TLR subtypes are also widely expressed in the gastrointestinal tract [14-16]. We have previously shown that high TLR9 expression in esophageal adenocarcinoma may indicate metastasis and poor prognosis [17]. In a more complex setting, the CpG nucleotides can be paradoxically used as anticancer reagents [18]. This is due to their capability to activate also the immunological defense mechanisms. Hence the same receptor, if activated in different cell type, can lead to dramatically different consequence.

TLR9 and other bacteria-recognizing receptors are of special interest in the normal and especially in the pathological processes in the esophagus, which is exposed to many exogenous molecules and putative pathogens by the oral route or via the gastroesophageal reflux. Esophageal cancer consists of two main histological types, namely squamous cell and adenocarcinoma. They differ from each other both by etiology and histopathological characters. Adenocarcinoma originates from Barrett's esophagus which develops through dysplasia to invasive cancer while squamous cell carcinoma develops directly from epithelial dysplasia to carcinoma. Esophageal squamous carcinoma is associated with smoking and alcohol consumption $[19,20]$ which both are known to be associated with alterations in oral microbiome [21, 22].

We hypothesized that the TLR9 could be an important link between bacterial exposure and cancer in the esoph- agus. In order to address this, we studied TLR9 expression in the normal esophageal squamous cell epithelium and during development and progression of esophageal squamous cell cancer.

\section{Materials and Methods}

\section{Patients and Samples}

The 51 samples of formalin-fixed and paraffin-embedded esophageal squamous cell carcinoma (diagnosed during the years 1984-2001) were collected from the archives of the Department of Pathology, Oulu University Hospital, Oulu, Finland. Of the tumor specimens, 12 contained areas of high-grade dysplasia, and they were all included in the analysis. In 24 cases, normal, nondysplastic squamous epithelium was also included in the analysis. The histological diagnosis and grading of the tumors were based on the WHO criteria. Forty-six of the patients underwent esophageal resection and 5 of the samples were biopsies. None of the patients received neoadjuvant therapy. Survival and the other relevant clinical data were obtained from the patients' clinical charts. The patient survival data was acquired from Statistics Finland (Helsinki). The clinical data associated with the cases are shown in table 1 . The study was approved by the Ethics Committee of Oulu University Hospital.

\section{Immunohistochemistry}

Immunohistochemistry was performed as follows. Sections of $4 \mu \mathrm{m}$ in thickness representing tumor, dysplastic or nonneoplastic areas were immunostained by a commercial mouse monoclonal TLR9 antibody (IMG-305A; Imgenex, San Diego, Calif., USA) with a dilution of 1:200 [23]. CD31 staining to visualize the blood vessels was performed with a monoclonal mouse IgG1 antibody obtained from DakoCytomation (Glostrup, Denmark; M 0823, clone JC70A, using the dilution of 1:300). Monoclonal rabbit IgG antibody, for detection of apoptotic cells, against active caspase-3 (AF835, lot CFZ33) was obtained from R\&D Systems (Minneapolis, Minn., USA) and used at 1:1,000 dilution. For assessment of proliferation, we used the Ki67 mouse monoclonal IgG1 antibody (NCL-Ki67-MM1, clone MM1; Novocastra Laboratories, Newcastle Upon Tyne, UK) using a dilution of 1:25. To validate our immunohistochemical stainings, we did two series of negative controls, by omitting the primary antibody and by replacing primary antibody with primary antibody isotype control. Prior to introduction of primary antibody to the specimen, a high-temperature antigen retrieval was done in citrate buffer (caspase-3) or Tris-EDTA buffer (TLR9, CD31, Ki67). Endogenous peroxidase activity was consumed by immersing the sections in 3\% hydrogen peroxide in absolute methanol for $15 \mathrm{~min}$, and to prevent non-specific binding $20 \%$ fetal calf serum was used. For immunohistochemical detection of the antibody reaction, the Dako Envision kit (Dako, Copenhagen, Denmark) was used. DAB (Zymed Laboratories Inc., San Francisco, Calif., USA) was used as a chromogen. Counterstainings were done with hematoxylin. We had to exclude 5 patients because specimens containing tumor mass from those patients were not available, resulting in a material of 46 patients with 43 resected and 3 biopsy samples.
Takala/Kauppila/Soini/Selander/ Vuopala/Lehenkari/Saarnio/Karttunen 
Table 1. Baseline characteristics of the patients

\begin{tabular}{|c|c|c|}
\hline & \multicolumn{2}{|c|}{ Patients } \\
\hline & $\mathrm{n}$ & $\%$ \\
\hline \multicolumn{3}{|l|}{ Age at diagnosis } \\
\hline$<60$ years & 9 & 17.6 \\
\hline $60-65$ years & 9 & 17.6 \\
\hline$>65$ years & 33 & 64.7 \\
\hline \multicolumn{3}{|l|}{ Sex } \\
\hline Male & 23 & 45 \\
\hline Female & 28 & 55 \\
\hline \multicolumn{3}{|l|}{ Tumor grade } \\
\hline 1 & 3 & 6.3 \\
\hline 2 & 27 & 56.3 \\
\hline 3 & 18 & 37.5 \\
\hline \multicolumn{3}{|l|}{ Tumor pT stage } \\
\hline 1 & 4 & 8.7 \\
\hline 2 & 9 & 19.6 \\
\hline 3 & 15 & 32.6 \\
\hline 4 & 18 & 39.1 \\
\hline \multicolumn{3}{|l|}{ Lymph nodes } \\
\hline Positive & 10 & 21.7 \\
\hline Negative & 36 & 78.3 \\
\hline \multicolumn{3}{|l|}{ Distal metastases } \\
\hline Positive & 9 & 19.6 \\
\hline Negative & 37 & 80.4 \\
\hline \multicolumn{3}{|l|}{ Tumor stage } \\
\hline $\mathrm{I}$ & 3 & 6.5 \\
\hline IIA & 19 & 41.3 \\
\hline IIB & 1 & 2.2 \\
\hline III & 14 & 30.4 \\
\hline IVA & 4 & 8.7 \\
\hline IVB & 5 & 10.9 \\
\hline
\end{tabular}

\section{Assessment of TLR9 Expression}

The immunostaining results were evaluated by two investigators (H.T. and J.H.K.). In case of a discrepancy in the assessment, a consensus was reached with a participation of a third investigator (T.J.K.). We assessed the intensity of immunostaining using a four-point scale $(0=$ absent, $1=$ weak, $2=$ moderate and $3=$ strong) and evaluated the percentage of positive cells in the tumor specimen at $10 \%$ accuracy. We also calculated the staining intensity score (histoscore) by multiplying the percentage of TLR9-expressing cells $(0-100)$ with the staining intensity $(0-3)$. In the analysis of normal epithelium, the staining intensity was assessed by using a four-point scale, as described above, and the estimate was based on impression of the whole area of normal squamous epithelium. In addition to the epithelial cells, the presence or absence of TLR9 expression in endothelial cells within the tumor and adjacent to normal epithelium was assessed.

\section{Computerized Analysis of TLR9 in Epithelium}

We used the MCID-Image analysis (InterFocus Imaging Ltd., Cambridge, UK) to objectively analyze the staining in normal and dysplastic esophageal squamous epithelium. A threshold level for the staining intensity and color were first adjusted subjectively to match the staining pattern of DAB. The epithelium was then divided into the basal, middle and luminal layers, each one of them consisting of one third of the thickness of the epithelium. These layers were then analyzed and the percentage of pixels exceeding the threshold for intensity counted resulting in a staining intensity value between 0.000 and 1.000 .

\section{Assessment of Cell Proliferation}

The determination of cell proliferation activity was based on the assessment of Ki-67/MIB-1 immunoreactive cells. The percentage of positively stained cells within the tumor tissue was evaluated in 10 high-power fields (HPF) for each tumor. Based on the median value of all cases, the proliferation rates were dichotomized to low or high levels of proliferation.

\section{Assessment of Apoptosis}

To identify apoptotic cells, 3'-end labeling of DNA (ApopTagTM In situ apoptosis detection kit; Oncor, Gaithersburg, Md., USA) was used according to the manufacturer's instructions. Briefly, the sections were dewaxed and dehydrated, after which they were incubated with $20 \mathrm{mg} / \mathrm{ml}$ proteinase K (Sigma Chemical Co., St. Louis, Mo., USA) at room temperature for $15 \mathrm{~min}$. Endogenous peroxidase activity was blocked by incubating the slides in $2 \%$ hydrogen peroxide in PBS, $\mathrm{pH}$ 7.2. The slides were then treated with terminal transferase enzyme and digoxigenin-labeled nucleotides, after which the anti-digoxigenin peroxidase solution was applied onto the slides. The color was developed with diaminobenzidine, after which the slides were counterstained with hematoxylin. As a positive control, a hyperplastic lymph node with germinal centers was used. The percentage of apoptotic cells was assessed in $10 \mathrm{HPF}$ in hot spot areas of each tumor. To estimate the percentage of apoptotic cells, the number of tumor cells in an HPF was calculated and the number of apoptotic events in the same HPF was then divided by the number of all tumor cells. Caspase-3 staining was assessed similarly to confirm the result given by $3^{\prime}$-end labeling of DNA, by counting the percentage of apoptotic cells in 10 HPF. For each case, the mean apoptosis rate was determined and the rates were also dichotomized based on the median value of all cases.

\section{Assessment of Vascular Density}

The vascular density was estimated as the number of positively stained (CD31) blood vessels in $1 \mathrm{HPF}$. Any endothelial cell cluster consisting of two or more cells was considered a single, countable microvessel. In each tumor section a minimum of 10 HPF were analyzed.

\section{Statistical Analysis}

SPSS for Windows (SPSS Inc., Chicago, Ill., USA) and Prism 4 for Macintosh (Graphpad, La Jolla, Calif., USA) were used for statistical analysis. The significance of associations was determined using Fisher's exact probability test, Pearson $\chi^{2}$ test, Mann-Whitney test, two-tailed t test and paired-samples $t$ test. Correlations were analyzed by using the Spearman rank correlation test. Survival was analyzed with the Kaplan-Meier curve, and significance of associations with the log-rank test. Probability values of $<0.05$ were considered significant. 


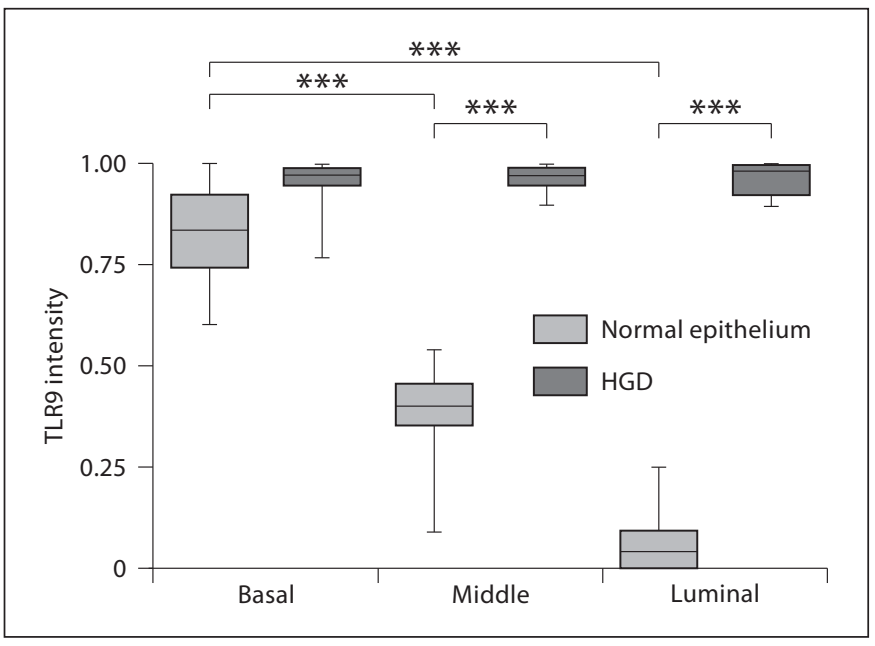

Fig. 1. Computerized quantitative analysis of TLR9 expression intensity in normal and dysplastic esophageal squamous epithelium. TLR9 expression in normal esophageal epithelium $(\mathrm{n}=24)$ is linearly decreased from the basal layer towards the apical layer ( $p<0.001$, paired samples $t$ test). In squamous high-grade dysplasia $(n=12)$, TLR9 expression was strong in full thickness of the epithelium. HGD = High-grade dysplasia. ${ }^{* *} \mathrm{p}<0.001$.

\section{Results}

TLR9 Expression in Normal Esophageal Squamous Epithelium

In normal squamous epithelium, intense cytoplasmic TLR9 immunoreaction was always present in the basal layer. Image analysis confirmed that the intensity of the immunoreaction decreased constantly linearly from the basal layers towards the superficial layers $(\mathrm{p}<0.001)$, and the latter were negative in the majority of cases suggesting that in normal esophageal epithelium these cells lose TLR9 expression as they mature (fig. 1, 3a-d).

\section{TLR9 Expression in Squamous Dysplasia of}

Esophagus

Squamous dysplasia was high grade in all 12 cases. In all of these cases, cytoplasmic TLR9 expression was present throughout the full thickness of the dysplastic epithelium, with moderate to strong intensity. Image analysis confirmed that there was no decreasing basal-luminal gradient as seen in the normal squamous epithelium (fig. 1, 3c-e). Such difference in the staining pattern and intensity allowed us to easily pinpoint the margin between dysplastic and normal squamous epithelium (fig. 3e). The overall expression of TLR9 was more intensive in dysplasia than in normal epithelium $(\mathrm{p}<0.001)$ and also higher than in the corresponding carcinomas $(\mathrm{p}<0.001$; fig. 2$)$.

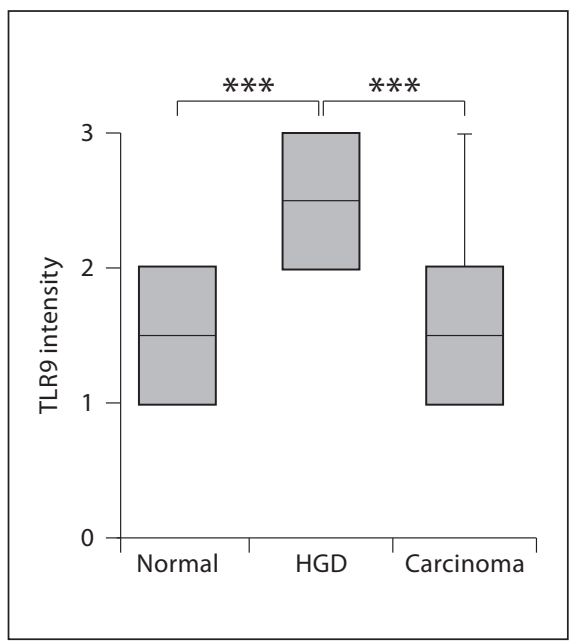

Fig. 2. Estimated TLR9 expression intensity in normal esophageal squamous epithelium and in neoplastic squamous cell lesions. TLR9 staining intensity in dysplasia $(\mathrm{n}=12)$ is significantly stronger than in normal esophageal epithelium $(n=24)$ or esophageal squamous cell carcinoma $(\mathrm{n}=46)$. Mann-Whitney test. HGD = High-grade dysplasia. ${ }^{* * *} \mathrm{p}<0.001$.

\section{TLR9 Expression in Squamous Cell Carcinoma of \\ Esophagus}

TLR9 expression was detected in all carcinomas, with weak immunoreactivity in $11 / 46(23.9 \%)$, moderate in $33 / 46(71.7 \%)$ and strong in $2 / 46$ (4.3\%) cases (fig. $3 \mathrm{~h}, \mathrm{f}, \mathrm{j}$ ). The reactivity for TLR9 was cytoplasmic, but also some nuclear positivity was observed in $7 / 46(15.6 \%)$ cases (fig. 3f). TLR9 expression was present in the majority of cancer cells (mean $89.7 \%$ of tumor cells).

High-grade (grades II and III) carcinomas exhibited higher TLR9 histoscore than low-grade (grade I) tumors $(\mathrm{p}<0.05$; table 2$)$. Among the patients, the depth of invasion was not associated with TLR9 staining intensity or TLR9 histoscore. Moderate and strong TLR9 intensity were associated with the presence of nodal $(p<0.05)$ or distant metastases $(\mathrm{p}<0.05$; table 2$)$. However, the TLR9 staining intensity was not associated with stage of esophageal squamous cell carcinoma (0-IIa/IIb-IVb; table 2) or with 5-year survival (data not shown).

\section{TLR9 Expression and Tumor Angiogenesis, \\ Proliferation and Apoptosis}

There was a negative correlation between TLR9 expression in tumor epithelium as measured by either histoscore or intensity, and the mean vessel density (CD31 staining; $\rho=-0.33 ; p<0.05)$. The mean vessel density in the tumor area was not related with tumor grade, or with 

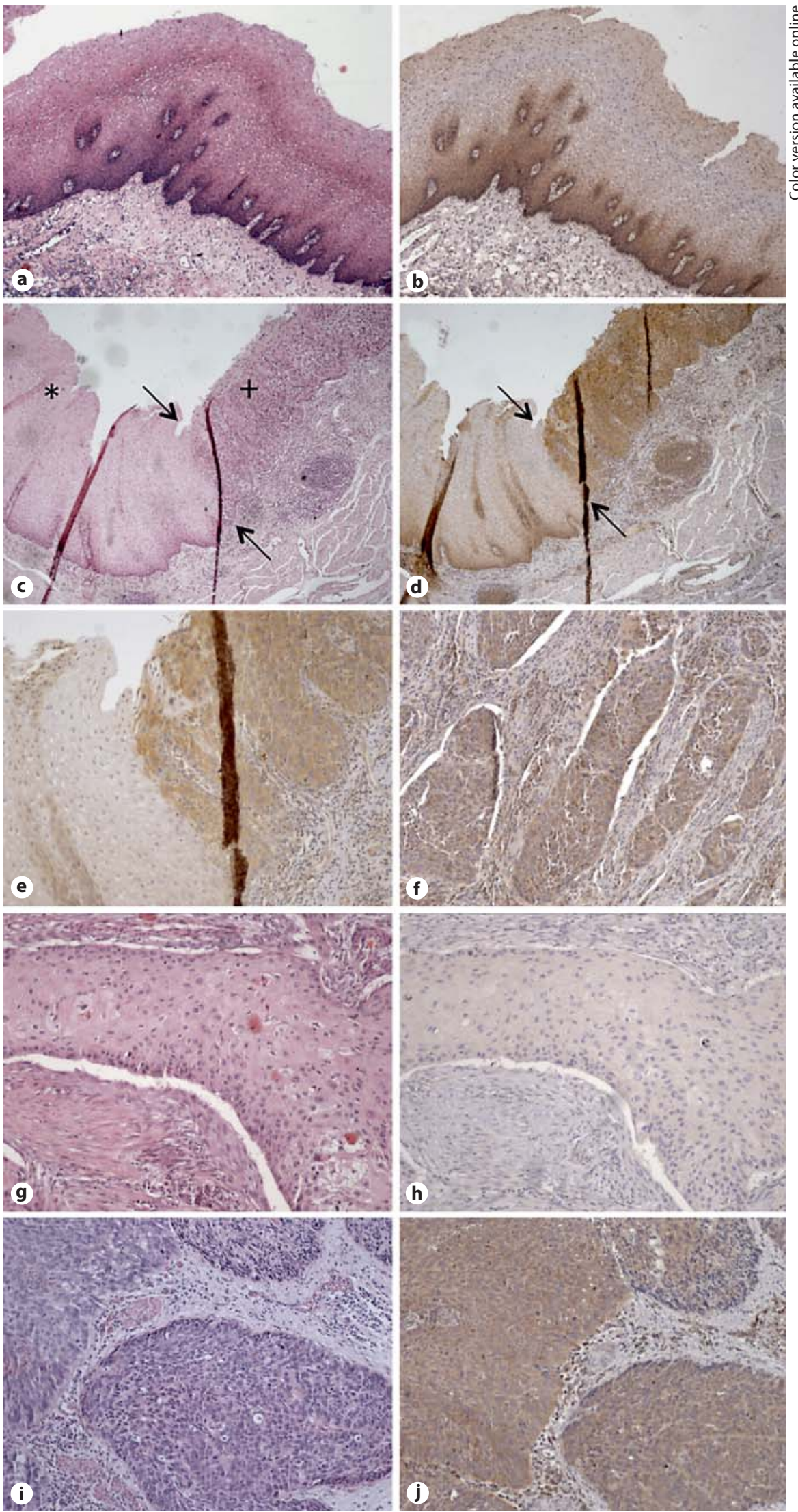

Fig. 3. Hematoxylin-eosin staining and TLR9 immunohistochemical stainings of normal esophageal squamous epithelium (a, b; 40X) demonstrating an intensive expression in the basal third of the epithelum and a gradual decrease in TLR9 expression intensity towards esophageal lumen. In esophageal squamous epithelium-dysplasia transition zone (c, d, 40×; e, 100×; transition marked with arrows, normal esophagus with an asterisk and dysplasia with a plus), an abrupt increase in TLR9 intensity is seen in the dysplasia (d, e). Examples of esophageal squamous cell carcinomas with different TLR9 expression patterns $(\mathbf{f}-\mathbf{j})$. Moderate TLR9 expression and nuclear positivity $(\mathbf{f} ; 100 \times)$, weak TLR9 expression $(\mathbf{g}, \mathbf{h} ; 100 \times)$ and strong TLR9 expression (i, $\mathbf{j} ; 100 \times)$ are shown. 
Table 2. Relationship between TLR9 immunopositivity and tumor characteristics

\begin{tabular}{|c|c|c|c|c|c|}
\hline \multirow[t]{2}{*}{ Variable } & \multirow{2}{*}{$\begin{array}{l}\mathrm{Pa}- \\
\text { tients }\end{array}$} & \multicolumn{3}{|c|}{ TLR9 immunopositivity } & \multirow[t]{2}{*}{$\mathrm{p}$} \\
\hline & & weak & moderate & strong & \\
\hline \multicolumn{6}{|l|}{ pT } \\
\hline $\mathrm{T}_{1,2}$ & 12 & $2(4.7)$ & $10(23.3)$ & 0 & \\
\hline $\mathrm{T}_{3,4}$ & 31 & $9(20.9)$ & $20(46.5)$ & $2(4.7)$ & NS \\
\hline \multicolumn{6}{|l|}{$\mathrm{N}$} \\
\hline Negative & 34 & $10(23.3)$ & $24(55.8)$ & 0 & \\
\hline Positive & 9 & $1(2.3)$ & $6(14)$ & $2(4.7)$ & $<0.05$ \\
\hline \multicolumn{6}{|l|}{ M } \\
\hline Negative & 35 & $10(23.3)$ & $25(58.1)$ & 0 & \\
\hline Positive & 8 & $1(2.3)$ & $5(11.6)$ & $2(4.7)$ & $<0.05$ \\
\hline \multicolumn{6}{|l|}{ Stage } \\
\hline I & 3 & 0 & $3(7.0)$ & 0 & \\
\hline IIA or IIB & 19 & $5(11.6)$ & $14(32.6)$ & 0 & \\
\hline III & 13 & $5(11.6)$ & $8(18.6)$ & 0 & \\
\hline IVA or IVB & 8 & $1(2.3)$ & $5(11.6)$ & $2(4.7)$ & NS \\
\hline \multicolumn{6}{|l|}{ Caspase 3} \\
\hline Low & 32 & $9(22.0)$ & $22(53.7)$ & $1(2.4)$ & \\
\hline High & 9 & $1(2.4)$ & $8(19.5)$ & 0 & NS \\
\hline \multicolumn{6}{|l|}{$\mathrm{Ki} 67$} \\
\hline Low & 17 & $3(7.3)$ & $14(34.1)$ & 0 & \\
\hline High & 24 & $8(19.5)$ & $15(36.6)$ & $1(2.4)$ & NS \\
\hline Grade & \multicolumn{4}{|c|}{ TLR9 histoscore } & $\mathrm{p}$ \\
\hline I & 150.7 & & & & \\
\hline II, III & 176.7 & & & & $<0.05^{1}$ \\
\hline
\end{tabular}

Figures in parentheses are percentages. NS = Not significant. Fisher's exact test was used for $\mathrm{p}$ values except where indicated otherwise.

${ }^{1}$ Mann-Whitney test.

presence of lymph node or distant metastases. Endothelial cells within the tumor appeared to be TLR9 positive in $43 \%(15 / 35)$ of cases, while in the area of normal esophagus they were positive in $90 \%(20 / 22)$ of cases $(\mathrm{p}<0.001)$.

There was no correlation between TLR 9 and proliferation, the percentage of apoptotic cells or caspase-3-positive cells. A positive correlation was found between the percentage of apoptotic cells and caspase-3-positive cells $(\rho=0.57, \mathrm{p}<0.001)$, as expected.

\section{Discussion}

TLR9-activating CpG nucleotides are being evaluated as immunological anticancer agents [24], but they have also been shown to promote in vitro invasion of various cancers $[11-13,25]$. The aim of our study was to evaluate the expression of TLR9 in normal, dysplastic and neoplastic esophageal squamous epithelium. In the gastrointestinal tract, TLR9 has been linked to inflammation-associated gastric cancer, but the expression and role of TLR9 in esophageal squamous cell dysplasia and cancer have not been established [9]. We detected a constant staining pattern of strong TL9 expression basally in the normal esophageal squamous cells. Furthermore, we detected that in squamous cell dysplasia this staining pattern changes to an intensive TLR9 expression that traverses the epithelium in full thickness. In addition, we show here that TLR9 expression is constantly present in esophageal squamous cell carcinoma, where strong TLR9 staining also associates with factors related to carcinoma progression.

The biological significance of the TLR9 abundance at the basal layer could be related to the epithelial proliferation and maturation status. We have earlier shown that TLR9 is expressed in mesenchymal stem cells [26]. There are no previous studies on squamous epithelial progenitor cells, but it is obvious that similar mechanisms could exist also in these cells. The fact that the most intensive TLR9 expression was seen in the proliferating basal cell layer might be linked to self-organization of these cells to produce the mature squamous cell structure. During the epithelial maturation and transit of cells toward the esophageal lumen, the expression of TLR9 appeared to decrease and eventually to disappear in the uppermost layers. There are no previous studies on TLR9 expression in esophageal squamous epithelium either. In normal cervical squamous epithelium TLR9 expression has been reported to be present in about $44 \%$ of cases, but no information staining pattern was provided [27]. In human skin, predominant TLR9 expression in the upper layers of normal epidermal keratinocytes has been reported [28]. In addition to methodological issues including different monoclonal antibody used, differences might be related to functional differences between keratinizing and nonkeratinizing squamous epithelia. The full biological significance of this decrement in the staining must be clarified in vitro. It is, however, evident that the loss of TLR9 at the apical surface leads to decreased TLR9 signaling and hence to tolerance towards bacterial DNA at the upper cell layer. On the other hand, if bacterial DNA manages to penetrate deeper layers of epithelium, this might inflict cell division and production of new epithelium in response to tissue wear. Interestingly, a similar expression pattern related to differentiation as in esophageal squamous epithelium has been recently reported in 
mesenchymal cells. Nurmenniemi et al. [26] discovered that undifferentiated human mesenchymal stem cells express TLR9 and that during differentiation into osteoblasts this expression decreases.

TLR9 expression was clearly more intensive in highgrade squamous dysplasia than in the normal squamous epithelium. In addition, expression was evenly present throughout the full thickness of the epithelium. Quite a similar change in the staining pattern of TLR9 in accordance with the histopathological grade of cervical intraepithelial neoplasia has been reported [27]. In contrast, in the study of Schmausser et al. [29], TLR9 was detected in normal gastric epithelium, but expression was lost in premalignant lesions including intestinal metaplasia and gastric dysplasia. These findings suggest that the role of TLR9 is different in squamous and columnar dysplasia. In squamous dysplasia, overexpression may be related to either lack of differentation, increased proliferation or both [27]. In our material, the intensive TLR9 expression clearly helped to locate the dysplastic lesions. Accordingly, the intensive TLR9 immunoreaction could be used as a marker of dysplastic esophageal squamocellular lesions.

In our study, all esophageal squamous cell carcinomas exhibited a widespread expression of TLR9. Moderate to strong TLR9 expression was associated with poor differentiation and presence of lymph node metastases or distant metastases. Similarly, extensive TLR9 expression and association with poor differentiation has also been noticed in breast and prostate cancers [23, 30]. In esophageal squamocellular carcinoma, TLR9 expression could be used as a marker of aggressive biological behavior. Inverse association was seen with the vascular density suggesting that possible tumor-promoting properties of TLR9 expression are not linked to induction of angiogenesis. Activation of tumor cell TLRs has been reported to promote tumor cell proliferation and resistance to apoptosis $[12,31]$. In this study, the TLR9 expression showed no association with tumor cell proliferation or apoptosis. No conclusions can be drawn from this finding because the natural TLR9 ligand in cancer remains unknown. However, there are other potential mechanisms linking TLR9 expression and prognosis of carcinoma, including modification of tumor cell invasion and metastasis by regulation of metalloproteinases [26].

The role and possible ligand of the originally microbial DNA recognizing TLR9 in the pathogenesis of esophageal squamous cell dysplasia and cancer remain unknown. Because of the short transit time of esophagus, its epithelial cells are normally exposed to oral microbes only for short periods of time. This suggests that there could also be a microbe-independent but TLR9-related pathway contributing to esophageal squamous cell carcinoma and disease progression. Whether the TLR9 senses DNA of dying cells from injured esophageal tissue or cancer tissue, or some other currently unknown ligand contributing to cancer development, is unknown, and should be evaluated in future studies. Endothelial TLR9 expression within esophageal carcinomas was downregulated compared with vessels outside the cancer. Previously, TLR9 has been detected in both animal and human endothelial cells, but characteristics of endothelial TLR9 expression in malignant tissue has remained unknown $[32,33]$. During inflammation, microbial recognition by endothelial TLRs contributes to structural and functional changes in endothelial cells including cytokine production and increased vascular permeability [34].

In conclusion, we show that in the normal esophageal squamous epithelium TLR9 is expressed in the basal parts of the epithelium. TLR9 is upregulated in highgrade dysplasias, which suggests that TLR9 might serve as a marker of esophageal squamous cell intraepithelial neoplasia. In esophageal squamous cell carcinomas, extensive TLR9 expression associated with high tumor grade and presence of lymph node and distant metastases. This finding should be validated in independent patient material using the same criteria for TLR9 analysis. Mechanisms of the upregulation of TLR9 in esophageal squamous malignancy remain speculative. However, our findings suggest that TLR9 might contribute to esophageal squamous cell carcinogenesis.

\section{Acknowledgements}

We thank Manu Tuovinen, Erja Tomperi and Mirja Vahera for their excellent technical assistance.

This research project was supported in part by grants from the Orion-Farmos research foundation (J.H.K.), the Finnish Cancer Foundation (K.S.S.) and the Cancer Foundation of Northern Finland (Pohjois-Suomen Syöpäyhdistys r.y.) (H.T.).

References

J Innate Immun 2011;3:631-638 
4 Hemmi H, Takeuchi O, Kawai T, Kaisho T, Sato S, Sanjo H, Matsumoto M, Hoshino K, Wagner H, Takeda K, Akira S: A Toll-like receptor recognizes bacterial DNA. Nature 2000;408:740-745.

5 Marshak-Rothstein A, Rifkin IR: Immunologically active autoantigens: the role of Tolllike receptors in the development of chronic inflammatory disease. Annu Rev Immunol 2007;25:419-441.

-6 Barrat FJ, Meeker T, Gregorio J, Chan JH, Uematsu S, Akira S, Chang B, Duramad O, Coffman RL: Nucleic acids of mammalian origin can act as endogenous ligands for Toll-like receptors and may promote systemic lupus erythematosus. J Exp Med 2005;202: 1131-1139.

7 Lande R, Gregorio J, Facchinetti V, Chatterjee B, Wang YH, Homey B, Cao W, Su B, Nestle FO, Zal T, Mellman I, Schroder JM, Liu YJ, Gilliet M: Plasmacytoid dendritic cells sense self-DNA coupled with antimicrobial peptide. Nature 2007;449:564-569.

8 Nestle FO, Conrad C, Tun-Kyi A, Homey B, Gombert M, Boyman O, Burg G, Liu YJ, Gilliet M: Plasmacytoid predendritic cells initiate psoriasis through interferon- $\alpha$ production. J Exp Med 2005;202:135-143.

$\checkmark 9$ Chang YJ, Wu MS, Lin JT, Sheu BS, Muta T, Inoue $\mathrm{H}$, Chen CC: Induction of cyclooxygenase-2 overexpression in human gastric epithelial cells by helicobacter pylori involves TLR2/TLR9 and C-SRC-dependent nuclear factor- $\mathrm{\kappa B}$ activation. Mol Pharmacol 2004;66:1465-1477.

-10 Merrell MA, Ilvesaro JM, Lehtonen N, Sorsa T, Gehrs B, Rosenthal E, Chen D, Shackley B, Harris KW, Selander KS: Toll-like receptor 9 agonists promote cellular invasion by increasing matrix metalloproteinase activity. Mol Cancer Res 2006;4:437-447.

-11 Ilvesaro JM, Merrell MA, Swain TM, Davidson J, Zayzafoon M, Harris KW, Selander KS: Toll like receptor-9 agonists stimulate prostate cancer invasion in vitro. Prostate 2007; 67:774-781.

12 Ren T, Xu L, Jiao S, Wang Y, Cai Y, Liang Y, Zhou Y, Zhou H, Wen Z: Tlr9 signaling promotes tumor progression of human lung cancer cell in vivo. Pathol Oncol Res 2009; 15: 623-630.

-13 Ilvesaro JM, Merrell MA, Li L, Wakchoure S, Graves D, Brooks S, Rahko E, Jukkola-Vuorinen A, Vuopala KS, Harris KW, Selander KS: Toll-like receptor 9 mediates CPG oligonucleotide-induced cellular invasion. Mol Cancer Res 2008;6:1534-1543.
4 Ishihara S, Rumi MA, Kadowaki Y, OrtegaCava CF, Yuki T, Yoshino N, Miyaoka Y, Kazumori H, Ishimura N, Amano Y, Kinoshita Y: Essential role of MD-2 in TLR4-dependent signaling during Helicobacter pyloriassociated gastritis. J Immunol 2004;173: 1406-1416.

15 Gewirtz AT, Navas TA, Lyons S, Godowski PJ, Madara JL: Cutting edge: bacterial flagellin activates basolaterally expressed TLR 5 to induce epithelial proinflammatory gene expression. J Immunol 2001;167:1882-1885.

16 Akhtar M, Watson JL, Nazli A, McKay DM: Bacterial DNA evokes epithelial IL-8 production by a MAPK-dependent, NF- $\kappa \mathrm{B}$-independent pathway. FASEB J 2003;17:13191321.

17 Kauppila JH TH, Selander KS, Lehenkari PP, Saarnio J, Karttunen TJ: Increased Toll-like receptor 9 expression indicates adverse prognosis in esophageal adenocarcinoma. Histopathology, in press

-18 Krieg AM, Yi AK, Matson S, Waldschmidt TJ, Bishop GA, Teasdale R, Koretzky GA, Klinman DM: CPG motifs in bacterial DNA trigger direct B-cell activation. Nature 1995; 374:546-549.

19 Falk GW: Risk factors for esophageal cancer development. Surg Oncol Clin N Am 2009; 18:469-485.

20 Toh Y, Oki E, Ohgaki K, Sakamoto Y, Ito S, Egashira A, Saeki H, Kakeji Y, Morita M, Sakaguchi Y, Okamura T, Maehara Y: Alcohol drinking, cigarette smoking, and the development of squamous cell carcinoma of the esophagus: molecular mechanisms of carcinogenesis. Int J Clin Oncol 2010;15: 135-144.

-21 Morita E, Narikiyo M, Yokoyama A, Yano A, Kamoi K, Yoshikawa E, Yamaguchi T, Igaki H, Tachimori Y, Kato H, Saito D, Hanada N, Sasaki H: Predominant presence of streptococcus anginosus in the saliva of alcoholics. Oral Microbiol Immunol 2005;20:362-365.

22 Delima SL, McBride RK, Preshaw PM, Heasman PA, Kumar PS: Response of subgingival bacteria to smoking cessation. J Clin Microbiol 2010;48:2344-2349.

23 Jukkola-Vuorinen A, Rahko E, Vuopala KS, Desmond R, Lehenkari PP, Harris KW, Selander KS: Toll-like receptor-9 expression is inversely correlated with estrogen receptor status in breast cancer. J Innate Immun 2008; 1:59-68.

24 Krieg AM: Toll-like receptor 9 (TLR9) agonists in the treatment of cancer. Oncogene 2008;27:161-167.
25 Chang YJ, Wu MS, Lin JT, Chen CC: Helicobacter pylori-induced invasion and angiogenesis of gastric cells is mediated by cyclooxygenase- 2 induction through $\operatorname{tr} 2 / \mathrm{t} \operatorname{lr} 9$ and promoter regulation. J Immunol 2005; 175 : $8242-8252$

26 Nurmenniemi S, Kuvaja P, Lehtonen S, Tiuraniemi S, Alahuhta I, Mattila RK, Risteli J, Salo T, Selander KS, Nyberg P, Lehenkari P: Toll-like receptor 9 ligands enhance mesenchymal stem cell invasion and expression of matrix metalloprotease-13. Exp Cell Res 2010;316:2676-2682.

27 Lee JW, Choi JJ, Seo ES, Kim MJ, Kim WY, Choi CH, Kim TJ, Kim BG, Song SY, Bae DS: Increased toll-like receptor 9 expression in cervical neoplasia. Mol Carcinog 2007;46: 941-947.

28 Miller LS, Sorensen OE, Liu PT, Jalian HR, Eshtiaghpour D, Behmanesh BE, Chung W, Starner TD, Kim J, Sieling PA, Ganz T, Modlin RL: TGF- $\alpha$ regulates TLR expression and function on epidermal keratinocytes. J Immunol 2005;174:6137-6143.

29 Schmausser B, Andrulis M, Endrich S, Muller-Hermelink HK, Eck M: Toll-like receptors TLR4, TLR5 and TLR9 on gastric carcinoma cells: an implication for interaction with helicobacter pylori. Int J Med Microbiol 2005;295:179-185.

30 Vaisanen MR, Vaisanen T, Jukkola-Vuorinen A, Vuopala KS, Desmond R, Selander KS, Vaarala MH: Expression of Toll-like receptor-9 is increased in poorly differentiated prostate tumors. Prostate 2010;70:817824.

- 31 Chiron D, Pellat-Deceunynck C, Maillasson M, Bataille R, Jego G: Phosphorothioatemodified tlr9 ligands protect cancer cells against trail-induced apoptosis. J Immunol 2009;183:4371-4377.

32 Erridge C, Burdess A, Jackson AJ, Murray C, Riggio M, Lappin D, Milligan S, Spickett CM, Webb DJ: Vascular cell responsiveness to Toll-like receptor ligands in carotid atheroma. Eur J Clin Invest 2008;38:713-720.

33 Schneberger D, Caldwell S, Suri SS, Singh B: Expression of Toll-like receptor 9 in horse lungs. Anat Rec (Hoboken) 2009;292:10681077.

34 Opitz B, Eitel J, Meixenberger K, Suttorp N: Role of toll-like receptors, NOD-like receptors and RIG-I-like receptors in endothelial cells and systemic infections. Thromb Haemost 2009;102:1103-1109. 